\title{
Feeling Good Despite EDS: The Effects of a 5-Week Online Positive Psychology Programme for Ehlers-Danlos-Syndromes Patients
}

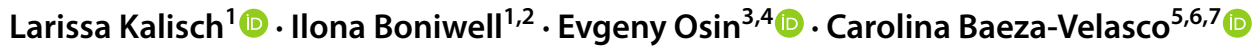 \\ Accepted: 6 September 2021 / Published online: 15 October 2021 \\ ( ) The Author(s), under exclusive licence to Springer Science+Business Media, LLC, part of Springer Nature 2021
}

\begin{abstract}
Ehlers-Danlos-Syndromes (EDS) is a group of hereditary, chronic and potentially disabling conditions. Few studies have tested the effects of psychological interventions to increase well-being in this population. We hypothesized that Positive Psychology Interventions (PPI), first applied to healthy and mentally ill subjects, can also be useful for people with somatic conditions and conducted a study to evaluate the efficacy of a 5-week online PPI designed to improve well-being in EDS patients. A sample of 132 EDS patients were allocated to three groups: assigned PPI, self-selected PPI, and waitlist controlgroup (WLC). Measures of positive and negative affect, pain disability, fatigue, and life satisfaction were administered before program start, 6 weeks later, and 1 month later. Satisfaction with the program was also evaluated. The results revealed that participants in the self-selected PPI-group, but not in the assigned PPI group, reported significantly lower levels of fatigue and higher levels of positive affect and life satisfaction compared to WLC after 6 weeks. There were no effects on negative affect and pain disability measures. Finally, $77 \%$ of the participants were satisfied or very satisfied with the program. These findings confirm and extend previous research by showing the efficacy of PPI for people with chronic illness under the condition that individuals can choose the program content. From a healthcare perspective, online PPIs could complement treatments aimed at symptom reduction and increase well-being in patients with EDS.
\end{abstract}

Keywords Positive psychology $\cdot$ Psychosocial intervention · Ehlers-Danlos-Syndromes · Fatigue $\cdot$ Positive affect · Online therapy

Larissa Kalisch

larissa@positive-force.com

1 Positran, Epone, France

2 Faculty of Science and Engineering Cambridge, Anglia Ruskin University (UK), Cambridge, UK

3 International Laboratory of Positive Psychology of Personality and Motivation, National Research University Higher School of Economics, Moscow, Russia

4 Laboratory LINP2, University of Paris Nanterre, Nanterre, France

5 LPPS, Université de Paris, 92100 Boulogne Billancourt, France

6 Department of Emergency Psychiatry and Acute Care, CHU Montpellier, Montpellier, France

7 IGT, University of Montpellier, CNRS, INSERM, Montpellier, France

\section{Introduction}

Ehlers-Danlos Syndromes (EDS) are a group of genetic diseases characterized by an abnormal production of collagens that affects connective tissue. Collagen is the most abundant protein in the human's body and responsible for the elasticity and strength of connective tissues such as skin, tendons, ligaments, walls of organs and blood vessels. EDS are considered as rare diseases with the total prevalence lying between 1 in 2500 and 1 in 5000 people (NIH U.S. National Library of Medicine, 2018; The Ehlers-Danlos Society, 2018). The classification of different EDS types was updated in 2017 by The International Consortium on the EDS and Related Disorders (Malfait et al., 2017) and includes 13 different subtypes. EDS affect all genders and ethnicities, although the prevalence is much higher in women and some subtypes are more prevalent in specific ethnicities, such as Ashkenazi Jews (The Ehlers-Danlos Society, 2018).

A large variety of symptoms are associated with EDS. Together with the lack of genetic testing for the most 
frequent subtype (hypermobile EDS), this results in an important delay of diagnosis after a long path of suffering by the affected persons (Hamonet et al., 2014; Scheper et al., 2015). Chronic (articulating) pain and excessive fatigue are the most frequent symptoms of EDS, leading to physical disability, impaired psychological well-being, and decreased quality of life (Hakim et al., 2017; Kalisch et al., 2020; Krahe, Adams, \& Nicholson, 2017). The psychosocial burden of EDS is high: fear of injury, chronic pain and disability provoke frustration and interpersonal discomfort, leading to social isolation. Up to one third of EDS patients shows clinical levels of depression and anxiety (Baeza-Velasco et al., 2018; Hershenfeld et al., 2016). Pharmacological treatments to reduce pain and psychiatric symptoms are not sufficient to break this vicious circle (Hamonet et al., 2014).

So far, research on interventions aimed to improve the psychological status of EDS patients is scarce. The study by Bathen et al. (2013) tested the effects of a multidisciplinary rehabilitation programme using a CBT approach in adults with hypermobile EDS. Muscle strengths and endurance training, together with pain coping sessions, had positive effects on performance of daily activities and reduced kinesiophobia - fear of movement due to pain (Vlaeyen \& Linton, 2000). Rahman, Daniel and Grahame (2014) investigated the benefits of a pain management programme for Joint Hypermobility Syndrome, which before 2017 was considered to be identical to hypermobile EDS. The programme took eight full days over a period of 6 weeks and was delivered by a multidisciplinary team. The sessions were based on the principles of CBT and included physiotherapy exercises. Researchers found a significant reduction in pain catastrophising, depression, anxiety, and frustration, as well as important improvements regarding the interference of pain, average pain intensity, and self-efficacy levels (Rahman, Daniel, \& Grahame, 2014).

Positive Psychology Interventions (PPI) focus on mobilising humans' cognitive and behavioural resources in order to promote life satisfaction and well-being through psychological processes, as opposed to interventions designed to reduce dysfunctional symptoms (Bolier et al., 2013; Hefferon \& Boniwell, 2011b; Proyer et al., 2016). Many studies in the last two decades have shown the efficacy of various low-intensity PPIs, such as counting positive events, practicing acts of kindness, expressing gratitude or using personal strengths, as summarised in the meta-analyses of Bolier et al. (2013) and Sin and Lyubomirsky (2009). PPIs were found to enhance well-being in the general population and to alleviate the symptoms of depression and anxiety in mental health patient samples. Interestingly, 26 out of 39 interventions reported by Bolier et al. (2013) can be self-administered and are increasingly delivered in an online format, sometimes accompanied by face-to-face instructions or support.
Lately, interest in PPIs for people suffering from chronic diseases has started to grow. Indeed, people suffering from chronic illness and pain experience a lot of negative emotions, which, in turn, hinders treatment adherence (Nsamenang \& Hirsch, 2015). Therefore, they could benefit from interventions that could increase their psychological resources and positive mood (Müller et al., 2020). Eight studies reviewed by Iddon, Dickson and Unwin (2016) have tested the effects of PPIs in individuals with non-malignant chronic pain lasting at least 3 months and provided evidence of improvement in psychological well-being, hope, pain selfefficacy, happiness, and life-satisfaction. Müller et al. (2016) found evidence of efficacy of a tailored computer-based PPI on enhancing well-being and reducing pain with individuals suffering from physical disability such as spinal cord injury, multiple sclerosis, neuromuscular disease or post-polio syndrome. Peters et al. (2017) compared the effects of an internet-based PPI "Happy Despite Pain" and a CBT intervention in fibromyalgia patients using a waitlist control group. They found both treatments to have comparable effects on happiness and depression, but no effect on physical disability.

From a motivational point of view, interventions corresponding to participants' preferences are expected to result in higher efficacy (Müller et al., 2016). According to SelfDetermination Theory by Ryan and Deci (2017), autonomy is one of the three basic psychological needs of humans, together with relatedness and competence. Autonomy-supporting activities do not only increase self-control and intrinsic motivation, but also facilitate counteracting the feeling of helplessness (Seligman, 1972), which is often present in people with chronic pain. Interventions providing individuals an active role in their own treatment boost self-efficacy, have higher adherence, and are shown to be more beneficial than those where individuals are simply assigned to a programme (Lyubomirsky et al., 2011; Schueller, 2011). Giving people the chance to choose the intervention contents and techniques according to their preferences and needs reduces dropout from an online positive psychology programme and results in higher enjoyment, leading to future usage of the skills learned (Schueller, 2011).

Given a lack of experimental research into psychological treatments for EDS patients, it is not surprising that the potential benefits of PPIs have not yet been explored in this population. The purpose of the present study was to examine the effects of the "Feeling Good Despite EDS" online intervention programme on positive and negative affect, pain interference, fatigue, life satisfaction, and satisfaction with the program in EDS patients. We expected pain interference, fatigue, and negative affect to decrease and life satisfaction and positive affect to increase in patients following the 5-week programme, compared to the waitlist group. Those effects were anticipated to be greater for participants 
selecting their exercises than for those being randomly assigned to exercises.

\section{Method}

\section{Participants, Design, and Procedure}

To test the online PPI, we used a design with two intervention groups and a waitlist control group in a sample of individuals diagnosed with any subtype of EDS. The Ehlers-Danlos Support UK Association, the Hypermobility Syndromes Association, EDS Wellness, Worldwide Ehlers-Danlos and the Dutch Association of Ehlers-Danlos Patients (VED) distributed the study's advertisement via newsletters and social media. Inclusion criteria given in the information letter were as follows: (a) minimum age of 18 , (b) EDS diagnosis, (c) being fluent in English language. The exclusion criterion was participation in any other intervention study at the same time. Eligible participants who completed the informed consent procedure were given access to the baseline questionnaire. The study was approved by the Psychology Departmental Research Ethics Panel (DREP) at Anglia Ruskin University.

Four-hundred seventeen participants completed the baseline questionnaire and were then systematically allocated to one of the three groups: assigned intervention group (A-PPI), self-selected intervention group (S-PPI) or the waitlist control group (WLC) based on the order of their inclusion in the study. Those in the WLC group received an email explaining that they were assigned to the second programme wave and that they would receive another questionnaire to complete in around 5 weeks' time. The flow of participants is presented in Fig. 1.

\section{Interventions}

Ten positive psychology topics were chosen among the Positive Action Cards developed by Boniwell (2014), based on former studies testing interventions for people with chronic health conditions (Bolier et al., 2013; Hausmann et al., 2017; Müller et al., 2016; Peters et al., 2017). The following topics were selected: using strengths in a new way, planning moments of socialising, reflecting on self-compassion, practicing savouring, mindful observation, planning a kindness day, setting goals and trying imagination, writing a gratitude letter, imagining the future Best Self, and recalling three positive things each day.

For each theme, work booklets consisting of different exercises and reflection tasks taking between 45 and $60 \mathrm{~min}$ in total per week, were designed. A randomized combination of five topics was allocated to each participant of the A-PPI group. The participants in the S-PPI group were sent a link briefly presenting the ten different topics and were asked to choose five of them. Every Friday, an email providing was sent to each participant with their weekly work booklet to start with on Monday and an evaluation link of the previous week. Participants received a reminder email on Monday morning. The post-intervention questionnaire was added to the fifth week evaluation link for the two intervention groups. The waitlist group was also provided with the post-intervention questionnaire 5 weeks after the baseline questionnaire.

\section{Instruments}

The questionnaires were administered in English. First, socio-demographic data were collected at baseline. Next, information about diagnosis, treatments, health care support, and medical and psychiatric comorbidities was gathered. The outcome measures were selected to reflect the constructs addressed by PPI or strongly related to EDS major symptoms.

\section{Fatigue}

To assess the levels of fatigue, we designed a discrete visual rating scale going from 0 to 10 with endpoints anchored by "no fatigue" and "worst imaginable fatigue".

\section{Pain Interference (Tait, Chibnall, \& Krause, 1990)}

Seven-item Pain Disability Index (PDI) measures pain interference in different live domains on an 11-point scale from 0 (no disability) to 10 (worst disability). The seven items are summed up to yield a total score ranging from 0 to 70 . Chibnall (1994) showed the PDI to be a reliable $(\alpha=.85)$ and valid measure of pain interference.

\section{Positive and Negative Affect (Watson, Clark, \& Tellegen, 1988)}

The Positive and Negative Affect Schedule (PANAS) is a 20 -item instrument with ten items measuring positive and negative affect respectively (e.g. "interested", "attentive", "hostile", "guilty") on a five-point Likert Scale (from 1 "very slightly or not at all" to 5 "extremely"). Respondents are asked to rate the extent to which they have felt that way during the past week. There is solid evidence for PANAS validity and reliability ( $\alpha=.89$ for PA and .85 for NA) (Crawford \& Henry, 2004; Ostir et al., 2005).

\section{Life Satisfaction (Diener et al., 1985)}

The five-item Satisfaction with Life Scale (SWLS) assesses life satisfaction on a seven-point Likert Scale (from 1 


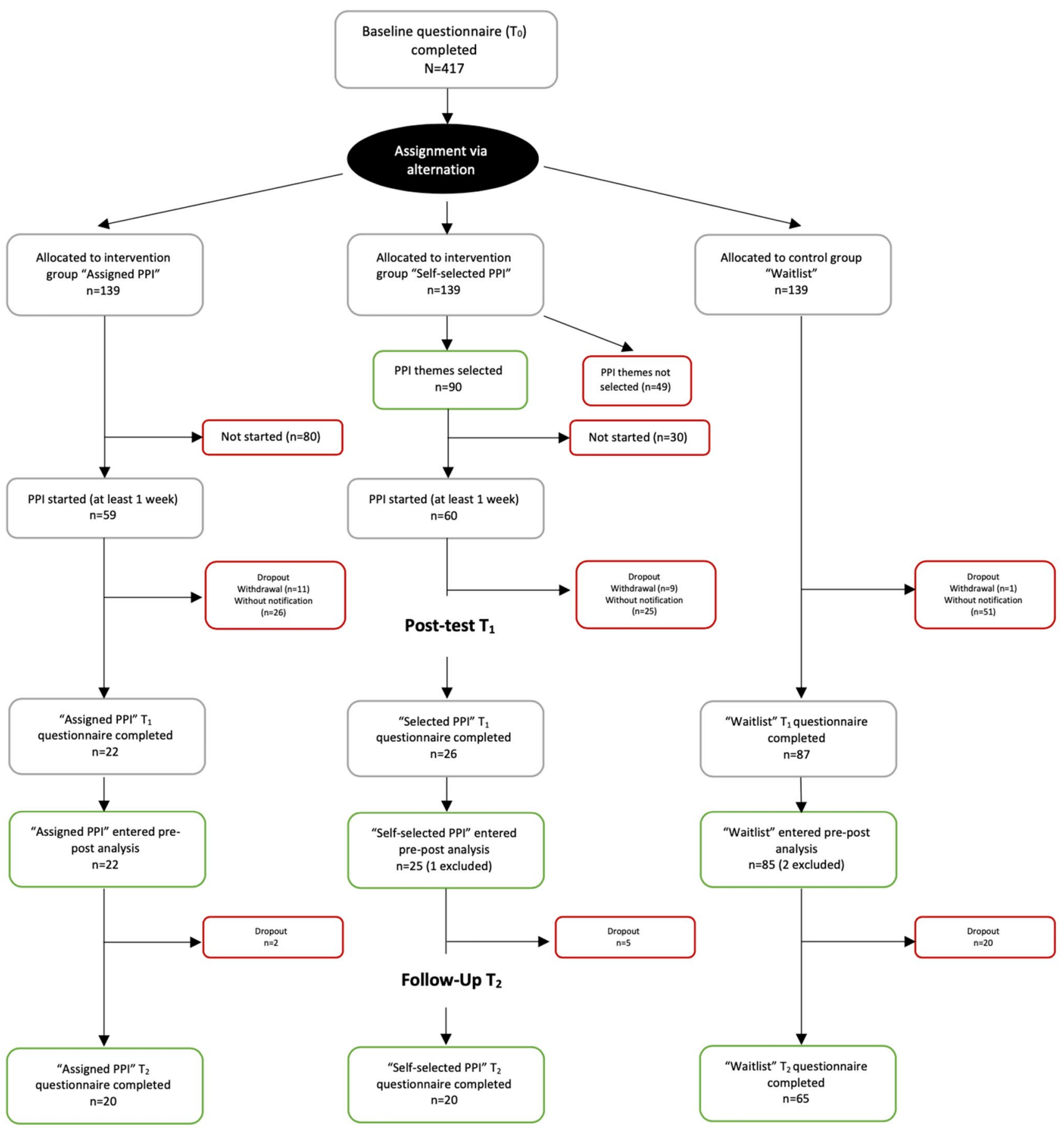

Fig. 1 Participants' flow

"strongly disagree" to 7 "totally agree"). The psychometric properties $(\alpha=.87)$ were tested by Pavot and Diener (1993).

\section{Client Satisfaction Questionnaire}

Client Satisfaction Questionnaire adapted to Internet-based interventions (CSQ-I) was included (Boss et al., 2016) in the post intervention questionnaire. Respondents were asked to rate eight items using a four-point Likert Scale from "does not apply to me" to "does totally apply to me".

\section{Satisfaction with Week's Exercises}

To get a more specific idea of the satisfaction with each positive psychology theme, participants were also asked to rate the week's exercises in the short weekly evaluation using a 
5-point Likert Scale from "I didn't enjoy them at all" (1) to "I enjoyed them very much" (5).

\section{Data Analysis}

The sample of 132 participants was used for the analysis, after removing two multivariate outliers and one more case due to missing data. To determine the effects of the programme, we used multivariate analysis of variance (MANOVA). No pairwise relationships between potential covariates (age, EDS type, treatment changes, psychological comorbidities, medical comorbidities and professional activity) and the outcome variables were found at baseline; therefore, no controlling for covariates was needed. Difference scores between post-treatment $\left(\mathrm{T}_{1}\right)$ and baseline $\left(\mathrm{T}_{0}\right)$ were computed for the following five variables used to assess the efficacy of the program: fatigue, pain interference, positive affect, negative affect, and life satisfaction. Significant MANOVA effects $(\mathrm{p}<.05)$ were further explored using one-way ANOVA with Tukey post hoc tests for each dependent variable. The same approach was used to assess the change from baseline to 1 month after the intervention with a subsample of individuals who completed the followup $(N=105)$.

\section{Results}

\section{Demographics}

$96.2 \%$ of the sample $(N=132)$ were women; the average age of participants was 37.7 years. More than half (53.8\%) of the participants had a UK nationality, 24.3\% another European nationality, $19.7 \%$ were Canadian or American, and $2.3 \%$ had another nationality. Most participants had a higher education $(48.5 \%)$ or a postgraduate degree $(28.8 \%)$. In terms of family status, $43.5 \%$ were single, $50.4 \%$ married or partnered, and $6.1 \%$ separated or divorced. More than half $(53.8 \%)$ did not have any children, $18.2 \%$ had one child, $18.2 \%$ two children, and $9.8 \%$ had three or more. In terms of work, $12.1 \%$ were employed full-time, $31.8 \%$ part-time, 9.8\% self-employed, $14.4 \%$ students, $4.5 \%$ retired, $6.1 \%$ homemaker, $6.8 \%$ unemployed, and $28 \%$ reported being unable to work.

\section{Clinical Data}

As far as EDS diagnosis is concerned, $84.8 \%$ had been diagnosed with hypermobile EDS, $8.3 \%$ with classical EDS, $2.3 \%$ with vascular EDS, and $4.5 \%$ with another EDS subtype. The mean age of diagnosis was 31.5 years with an average delay in diagnosis of 21.4 years $(\mathrm{SD}=13.26)$. Over half $(59.1 \%)$ of the participants reported taking painkillers,
$38.6 \%$ indicated they took other drugs, and $41.7 \%$ benefited from Vitamin D treatment. Almost two thirds (64.4\%) went to physiotherapy, $20.5 \%$ had occupational therapy, and $12.1 \%$ were in psychotherapy. Only $3.8 \%$ had no treatment. Medical comorbidities were reported by $31.8 \%$, and psychiatric comorbidities were reported by $45.5 \%$ of the sample, a quarter of which suffered from both mood and anxiety disorders.

\section{Intervention Efficacy}

One-way ANOVA did not reveal any significant differences between the baseline scores of the three groups. MANOVA using difference scores has revealed a significant difference between the three groups on the five dependent variables $[F(10,250)=1.90, p<.05$; Wilks' $\Lambda=.864$; partial $\left.\eta^{2}=.071\right]$. Follow-up univariate ANOVAs (see Table 1) showed that change scores for fatigue, satisfaction with life, and positive affect differed significantly across the three groups. No significant differences were found for pain disability and negative affect. Based on Tukey post hoc test, at $\mathrm{T}_{1}$ the WLC group reported significantly higher fatigue $(p=.028)$, as well as lower satisfaction with life $(p=.033)$ and positive affect ( $p=.014)$, compared to the S-PPI group. The only significant difference between the two intervention groups was found for positive affect: the A-PPI group reported lower scores than the S-PPI group $(p=.006)$.

At 1-month follow-up, the difference between the three groups in change scores from baseline for the combined five dependent variables was again statistically significant $[F(10$, 194) $=2.33, p<.05$; Wilks' $\Lambda=.797$; partial $\left.\eta^{2}=.107\right]$. Follow-up univariate ANOVAs revealed significant differences in satisfaction with life $[F(2,101)=4.916, p<.01$; partial $\left.\eta^{2}=.089\right]$ and positive affect $[F(2,101)=5.839$, $p<.01$; partial $\left.\eta^{2}=.104\right]$. A weaker difference in fatigue was observed, but did not reach statistical significance $[F(2$, $101)=2.141, p>.05 ;$ partial $\left.\eta^{2}=.041\right]$. A significant difference between the three groups in pain disability was found $\left[F(2,101)=3.631, p<.05\right.$; partial $\left.\eta^{2}=.067\right]$. There was no difference for negative affect $[F(2,101)=1.007, p>.05$; partial $\left.\eta^{2}=.020\right]$. According to Tukey post hoc test, the follow-up satisfaction with life and positive affect scores in the S-PPI group were significantly higher not only compared to the WLC group, but also to the A-PPI group. The pain disability score was higher in the A-PPI group, compared to the S-PPI group.

\section{Programme Satisfaction}

The overall programme satisfaction was good, showing that more than three quarters $(76.6 \%)$ of the participants were rather satisfied or very satisfied and only $4.3 \%$ were not satisfied at all. No significant difference in programme 
Table 1 Means and standard deviations of outcome variables per group and per timepoint

\begin{tabular}{|c|c|c|c|c|c|c|c|c|c|}
\hline & & \multicolumn{3}{|l|}{ Score, M (SD) } & \multicolumn{3}{|c|}{ Score difference from $\mathrm{T}_{0}, \mathrm{M}(\mathrm{SD})$} & \multirow[t]{2}{*}{$F$} & \multirow[t]{2}{*}{$\eta^{2}$} \\
\hline & & A-PPI & S-PPI & Wait-list & A-PPI & S-PPI & Wait-list & & \\
\hline \multirow[t]{3}{*}{ Pain Disability } & $\mathrm{T}_{0}$ & $28.59(15.95)$ & $33.48(9.38)$ & $32.65(13.21)$ & & & & & \\
\hline & $\mathrm{T}_{1}$ & $27.50(16.32)$ & $31.00(8.88)$ & $33.47(12.58)$ & $-1.09(0.37)^{\mathrm{a}}$ & $-2.48(0.50)^{\mathrm{a}}$ & $0.82(0.63)^{\mathrm{a}}$ & 1.50 & .023 \\
\hline & $\mathrm{T}_{2}$ & $38.80(13.21)$ & $35.55(9.92)$ & 37.05 (14.97) & $10.21(2.74)^{\mathrm{a}}$ & $2.07(0.54)^{b}$ & $4.40(1.76)^{\mathrm{ab}}$ & 3.63 & .067 \\
\hline \multirow[t]{3}{*}{ Fatigue } & $\mathrm{T}_{0}$ & $4.86(2.10)$ & $5.08(1.35)$ & $5.28(1.67)$ & & & & & \\
\hline & $\mathrm{T}_{1}$ & $5.18(2.15)$ & $4.44(2.24)$ & $5.84(1.77)$ & $0.32(0.05)^{\mathrm{ab}}$ & $-0.64(0.89)^{\mathrm{a}}$ & $0.56(0.10)^{\mathrm{b}}$ & $3.39 *$ & .050 \\
\hline & $\mathrm{T}_{2}$ & $6.68(1.60)$ & $5.70(2.15)$ & $6.45(1.42)$ & $1.86(0.50)^{\mathrm{a}}$ & $0.62(0.80)^{\mathrm{a}}$ & $1.17(0.25)^{\mathrm{a}}$ & 2.14 & .041 \\
\hline \multirow[t]{3}{*}{ Positive Affect } & $\mathrm{T}_{0}$ & $28.27(9.01)$ & $26.20(6.92)$ & $27.14(8.20)$ & & & & & \\
\hline & $\mathrm{T}_{1}$ & $27.05(7.52)$ & $30.64(7.31)$ & $27.56(7.59)$ & $-0.12(1.49)^{\mathrm{a}}$ & $4.44(0.39)_{\mathrm{b}}$ & $0.42(0.61)_{\mathrm{a}}$ & $5.59 * *$ & .080 \\
\hline & $\mathrm{T}_{2}$ & $28.60(7.89)$ & 30.65 (7.66) & $27.75(8.42)$ & $0.33(1.12)^{\mathrm{a}}$ & $4.45(0.74)_{\mathrm{b}}$ & $0.61(0.22)_{\mathrm{a}}$ & $5.84 * *$ & .104 \\
\hline \multirow[t]{3}{*}{ Negative Affect } & $\mathrm{T}_{0}$ & $23.45(10.08)$ & $24.28(8.79)$ & $25.00(9.06)$ & & & & & \\
\hline & $\mathrm{T}_{1}$ & 22.14 (9.19) & $21.68(6.87)$ & $24.20(8.82)$ & $-1.31(0.89)^{\mathrm{a}}$ & $-2.60(1.92)_{\mathrm{a}}$ & $-0.80(0.24)_{a}$ & 0.61 & .009 \\
\hline & $\mathrm{T}_{2}$ & $21.90(9.39)$ & $20.70(7.02)$ & $22.85(8.46)$ & $-1.55(0.69)^{\mathrm{a}}$ & $-3.58(1.77)^{\mathrm{a}}$ & $-2.15(0.60)^{\mathrm{a}}$ & 1.01 & .020 \\
\hline \multirow[t]{3}{*}{ Life satisfaction } & $\mathrm{T}_{0}$ & $18.91(7.78)$ & $16.24(6.70)$ & $16.61(7.38)$ & & & & & \\
\hline & $\mathrm{T}_{1}$ & $19.23(8.54)$ & $19.32(6.97)$ & $17.16(7.74)$ & $0.32(0.76)^{\mathrm{ab}}$ & $3.08(0.27)^{\mathrm{a}}$ & $0.55(0.36)^{\mathrm{b}}$ & $3.35^{*}$ & .052 \\
\hline & $\mathrm{T}_{2}$ & $19.35(7.93)$ & $20.30(7.77)$ & $18.49(7.31)$ & $0.55(0.15)^{\mathrm{a}}$ & $4.06(1.07)^{\mathrm{b}}$ & $1.88(0.07)^{\mathrm{a}}$ & $4.92 * *$ & .089 \\
\hline
\end{tabular}

$N=132$ at $\mathrm{T}_{1}$ Post-intervention (A-PPI $\mathrm{n}=22$, S-PPI $\mathrm{n}=25$, Waitlist $\mathrm{n}=85$ ); $N=105$ at $\mathrm{T}_{2}$ Follow-up (A-PPI $\mathrm{n}=20, \mathrm{~S}$-PPI $\mathrm{n}=20$, Waitlist $\mathrm{n}=65$ ). Means with different subscripts differ at the $p=.05$ level according to Tukey HSD post hoc test

$* p=.05, * * p=.01$

Means with different subscripts differ at the $p=.05$ level according to Tukey HSD post hoc test

Means with different lowercase letters indicate differences at the $p=.05$ level according to Tukey HSD post hoc test

Table 2 Evaluation and selection frequency of the ten PPI themes

\begin{tabular}{lll}
\hline PPI themes & $\begin{array}{l}\text { Evaluation of theme } \\
(N=47)(\text { Min. 1, Max. } \\
5)(M)\end{array}$ & $\begin{array}{l}\text { Selection by } \\
\text { S-PPI }(N=90) \\
(\%)\end{array}$ \\
\hline Spot the Positives & 4.24 & 56.7 \\
Mindful observation & 3.88 & 62.2 \\
Savouring & 3.77 & 44.4 \\
Socialising & 3.76 & 33.3 \\
A Kindness Day & 3.71 & 28.9 \\
Self-compassion & 3.67 & 77.8 \\
Using strengths in a new & 3.51 & 57.8 \\
$\quad$ way & & \\
Best Possible Self & 3.50 & 65.7 \\
Gratitude Visit & 3.41 & 16.7 \\
Hope Quest & 3.12 & 56.7 \\
\hline
\end{tabular}

satisfaction was found between the A-PPI and the S-PPI group. As shown in Table 2, Spot the Positives got the highest rating $(M=4.24)$ among the 10 positive psychology themes, whereas Hope Quest turned out to be the least appreciated theme $(M=3.12)$ by the participants who completed it $(N=47)$. In terms of choice frequency, Self-Compassion (77.8\%), Best Possible Self (65.7\%), Mindful observation (62.2\%) and Using strengths in a new way $(57.8 \%)$ were the most often selected exercises by the participants from the self-selected intervention group $(N=90)$.

\section{Discussion}

In this study, we examined the effects of a 5-week online PPI designed to enhance well-being in individuals with EDS. We observed that online exercises based on positive psychology have moderate benefits in reducing fatigue, as well as increasing positive affect and satisfaction with life for participants who chose their own composition of the programme (S-PPI group). These effects were maintained at 1-month follow-up for positive affect and satisfaction with life, but not for fatigue. For those assigned to a predetermined intervention programme (A-PPI group), there were no positive effects compared to the WLC. As far as pain disability is concerned, no differences between the three groups were found at post-test. However, patients participating in the A-PPI group reported higher pain disability than those in the S-PPI group at 1-month follow-up. We did not find any differences between the groups for negative affect at any time point.

Similar results were reported by Müller et al. (2016), who observed that satisfaction with life and positive affect increased, but negative affect remained unchanged after a tailored PPI in individuals with chronic pain and physical 
disability. Similarly, a study of 5-week PPI for patients with multiple sclerosis (Leclaire et al., 2018) found improvements in fatigue (vitality), but no effect for negative affect. The findings by Peters et al. (2017) also suggest that the benefits of PPI might be restricted to the affective, rather than the physical domain: the functioning related to pain was unaffected by their intervention and the decrease in fatigue turned out to be a short-term effect, whereas the positive effects on satisfaction with life and positive affect were sustained at 1 month after the PPI.

Our findings suggest that PPIs may not be helpful to reduce pain disability in people with EDS. Those who are affected suffer from multi-systemic painful symptoms (Hamonet et al., 2014), which results in a high burden of disease (Murray et al., 2013); many patients are dependent on others in multiple life domains and are sometimes only able to move in a wheelchair (Hamonet et al., 2014). Thus, patients will probably always experience some pain interference in everyday life. In addition, the short duration of the PPI may also explain the lack of change in pain disability levels.

As we had expected, our results suggest that when individuals have some freedom to design their intervention, they are more likely to report increased well-being afterwards. This is not the case for individuals assigned to an entirely pre-designed programme. Indeed, there is evidence that S-PPI are more beneficial than those that are assigned (Higgins et al., 2010; Schueller, 2011). This effect is explained well by Self-Determination theory with vast empirical evidence showing the importance of autonomy for performance and treatment adherence. By being able to choose their own five themes, participants could receive an intervention better adjusted to their individual preferences and needs. Our findings corroborate the evidence concerning the various positive effects of self-concordant exercises (Schueller, 2011).

In the present study, the number of participants who completed the baseline questionnaire was reduced by two thirds $(67.6 \%)$ at post-treatment (82.3\% for PPI groups, $37.5 \%$ for WLC). Even though the attrition rate was very high, it is not surprising, given the virtual modality of the program. Previous studies of online self-administered PPIs have reported comparable attrition rates: $69.8 \%$ for a 3-week intervention to promote well-being (Mitchell et al., 2009 ) and $61.8 \%$ (75.9\% in the experimental group) for an 8 -week positive mindfulness program (Ivtzan et al., 2016). Thus, although internet-based interventions were shown to be efficient, the high rate of attrition appears to be their main methodological challenge (Eysenbach, 2002, 2005). An explanation might be that participants simply lose their interest, given that interventions like the "Feeling good despite EDS" programme are of low intensity (45-60 min per week) and have little structure (Bennett \& Glasgow, 2009). The present intervention did not include any inperson interaction, which could increase motivation and persistence (Mitchell, Vella-Brodrick, \& Klein, 2010). The high attrition rate might also be related to the characteristics of the sample: we observed that the participants who dropped out benefited less often from foot orthosis, physiotherapy, and psychotherapy, took more painkillers, suffered from more psychiatric comorbidities, scored higher on pain disability and negative affect. Based on this, one could assume that the participants who abandoned the study were experiencing higher burden due to their EDS and had more difficulty to complete the program.

As far as overall treatment satisfaction is concerned, the 5 -week PPI was highly rated by participants. Regarding theme preference, shorter exercises that were practiced more often were more highly appreciated by participants than reflection tasks that lasted 30 to $40 \mathrm{~min}$.

Limitations of the study include small sample size, the fact that EDS diagnosis was based on self-report, and absence of complete randomisation. Furthermore, the efficacy of each theme proposed remains unknown, even though it is likely that some exercises may have been more beneficial for some participants than others. Similarly, it remains unknown whether specific combinations and/or sequences of exercises might be more useful than others. Future research with a more rigorous design could confirm and further explore the benefits of PPIs for EDS patients. Despite these limitations, the study contributes to the scarce but growing body of interventional research in EDS patients by testing the usefulness of PPIs in this specific population for the first time. In addition online-based interventions become increasingly relevant for patients living with reduced mobility and since the beginning of the COVID-19 pandemic.

In the context of EDS, a treatment approach that involves focusing on other things than one's illness seems to be a positive complement to medical treatments and might be applicable to the majority of life-long conditions. Furthermore, it counteracts the common criticism against positive psychology (Lazarus, 2003; Wong, 2011) suggesting that only healthy people might benefit from PPIs (Hefferon \& Boniwell, 2011a). Our findings suggest that healthcare professionals could take more effort to involve the client when it comes to programme design. As a result, persons suffering from EDS would have an active role in moving towards a better quality of life, rather than feeling helpless, which is a widespread phenomenon among people with chronic pain (Karasawa et al., 2019).

Acknowledgements We wish to thank all the EDS patients who participated in our study and acknowledge the support of the Ehlers-Danlos Support UK, Ehlers-Danlos Society, Hypermobility-Syndromes Association, EDS Wellness and the Netherlands Vereniging Van EhlersDanlos Patienten in participant recruitment. 
Funding This research did not receive any specific funding. The contribution of EO was supported by the HSE University Basic Research Program

\section{Declarations}

Conflict of interest The authors have no conflict of interest to disclose.

Ethical Approval The study received ethical approval from the Psychology Departmental Research Ethics Panel (DREP) at Anglia Ruskin University.

\section{References}

Baeza-Velasco, C., Bourdon, C., Montalescot, L., de Cazotte, C., Pailhez, G., Bulbena, A., \& Hamonet, C. (2018). Low- and high-anxious hypermobile Ehlers-Danlos syndrome patients: Comparison of psychosocial and health variables. Rheumatology International, 38(5), 871-878.

Bathen, T., Hångmann, A. B., Hoff, M., Andersen, L. Ø., \& RandHendriksen, S. (2013). Multidisciplinary treatment of disability in Ehlers-Danlos syndrome hypermobility type/hypermobility syndrome: A pilot study using a combination of physical and cognitive-behavioral therapy on 12 women. American Journal of Medical Genetics Part A, 161(12), 3005-3011. https://doi.org/ 10.1002/ajmg.a.36060

Bennett, G. G., \& Glasgow, R. E. (2009). The delivery of public health interventions via the Internet: Actualizing their potential. Annual Review of Public Health, 30(1), 273-292. https://doi.org/10.1146/ annurev.publhealth.031308.100235

Bolier, L., Haverman, M., Westerhof, G. J., Riper, H., Smit, F., \& Bohlmeijer, E. (2013). Positive psychology interventions: A metaanalysis of randomized controlled studies. BMC Public Health. https://doi.org/10.1186/1471-2458-13-119

Boniwell, I. (2014). Positive Action Cards. Positran.

Boss, L., Lehr, D., Reis, D., Vis, C., Riper, H., Berking, M., \& Ebert, D. D. (2016). Reliability and validity of assessing user satisfaction with web-based health interventions. Journal of Medical Internet Research, 18(8), e234. https://doi.org/10.2196/jmir.5952

Chibnall, J. (1994). The pain disability index: Factor structure and normative data. Archives of Physical Medicine and Rehabilitation, 75(10), 1082-1086. https://doi.org/10.1016/0003-9993(94) 90082-5

Crawford, J. R., \& Henry, J. D. (2004). The positive and negative affect schedule (PANAS): Construct validity, measurement properties and normative data in a large non-clinical sample. British Journal of Clinical Psychology, 43(3), 245-265.

Diener, E., Emmons, R. A., Larsen, R. J., \& Griffin, S. (1985). The satisfaction with life scale. Journal of Personality Assessment, 49(1), 71-75. https://doi.org/10.1207/s15327752jpa4901_13

Eysenbach, G. (2002). Issues in evaluating health websites in an Internet-based randomized controlled trial. Journal of Medical Internet Research, 4(3), e17. https://doi.org/10.2196/jmir.4.3.e17

Eysenbach, G. (2005). The law of attrition. Journal of Medical Internet Research, 7(1), e11. https://doi.org/10.2196/jmir.7.1.e11

Hakim, A., De Wandele, I., O'Callaghan, C., Pocinki, A., \& Rowe, P. (2017). Chronic fatigue in Ehlers-Danlos syndrome-hypermobile type. American Journal of Medical Genetics Part C: Seminars in Medical Genetics, 175(1), 175-180. https://doi.org/10.1002/ ajmg.c. 31542

Hamonet, C., Gompel, A., Raffray, Y., Zeitoun, J. D., Delarue, M., Vlamynck, E., ... Mazaltarine, G. (2014). Les multiples douleurs du syndrome d'Ehlers-Danlos. Description et proposition d'un protocole thérapeutique. Douleurs: Evaluation-Diagnostic-Traitement, 15(6), 264-277. https://doi.org/10.1016/j.douler.2014.09.003.

Hausmann, L. R. M., Youk, A., Kwoh, C. K., Ibrahim, S. A., Hannon, M. J., Weiner, D. K., ... Parks, A. (2017). Testing a positive psychological intervention for osteoarthritis. Pain Medicine, 18(10), 1908-1920. https://doi.org/10.1093/pm/pnx141

Hefferon, K., \& Boniwell, I. (2011a). Chapter 1: Introduction to positive psychology. In Positive psychology: Theory, research and applications. (pp. 1-21). McGraw-Hill International (UK) Ltd. http://public.eblib.com/choice/publicfullrecord.aspx?p=729517.

Hefferon, K., \& Boniwell, I. (2011b). Chapter 8: Positive psychology interventions. In Positive psychology: Theory, research and applications (pp. 150-174). McGraw-Hill International (UK) Ltd. http://public.eblib.com/choice/publicfullrecord.aspx?p=729517.

Hershenfeld, S. A., Wasim, S., McNiven, V., Parikh, M., Majewski, P., Faghfoury, H., \& So, J. (2016). Psychiatric disorders in EhlersDanlos syndrome are frequent, diverse and strongly associated with pain. Rheumatology International, 36(3), 341-348.

Higgins, E. T., Cesario, J., Hagiwara, N., Spiegel, S., \& Pittman, T. (2010). Increasing or decreasing interest in activities: The role of regulatory fit. Journal of Personality and Social Psychology, 98(4), 559-572. https://doi.org/10.1037/a0018833

Iddon, J. E., Dickson, J. M., \& Unwin, J. (2016). Positive psychological interventions and chronic non-cancer pain: A systematic review of the literature. International Journal of Applied Positive Psychology, 1(1-3), 133-157. https://doi.org/10.1007/s41042-016-0003-6

Ivtzan, I., Young, T., Martman, J., Jeffrey, A., Lomas, T., Hart, R., \& Eiroa-Orosa, F. J. (2016). Integrating mindfulness into positive psychology: A randomised controlled trial of an online Positive Mindfulness Program. Mindfulness, 7(6), 1396-1407. https://doi. org/10.1007/s12671-016-0581-1

Kalisch, L., Hamonet, C., Bourdon, C., Montalescot, L., de Cazotte, C., \& Baeza-Velasco, C. (2020). Predictors of pain and mobility disability in the hypermobile Ehlers-Danlos syndrome. Disability and Rehabilitation, 42(25), 3679-3686.

Karasawa, Y., Yamada, K., Iseki, M., Yamaguchi, M., Murakami, Y., Tamagawa, T., et al. (2019). Association between change in selfefficacy and reduction in disability among patients with chronic pain. PLoS ONE, 14(4), e0215404. https://doi.org/10.1371/journ al.pone. 0215404

Krahe, A. M., Adams, R. D., \& Nicholson, L. L. (2017). Features that exacerbate fatigue severity in joint hypermobility syndrome/ Ehlers-Danlos syndrome-Hypermobility type. Disability and Rehabilitation. https://doi.org/10.1080/09638288.2017.1323022

Lazarus, R. S. (2003). Does the positive psychology movement have legs? Psychological Inquiry, 14(2), 93-109.

Leclaire, K., Cecil, A., LaRussa, A., Stuart, F., Hemond, C. C., Healy, B. C., ... Glanz, B. I. (2018). Short report: A pilot study of a group positive psychology intervention for patients with multiple sclerosis. International Journal of MS Care, 20(3), 136-141. https://doi.org/10.7224/1537-2073.2017-002.

Lyubomirsky, S., Dickerhoof, R., Boehm, J. K., \& Sheldon, K. M. (2011). Becoming happier takes both a will and a proper way: An experimental longitudinal intervention to boost well-being. Emotion, 11(2), 391-402. https://doi.org/10.1037/a0022575

Malfait, F., Francomano, C., Byers, P., Belmont, J., Berglund, B., Black, J., ... Tinkle, B. (2017). The 2017 international classification of the Ehlers-Danlos syndromes. American Journal of Medical Genetics Part C: Seminars in Medical Genetics, 175(1), 8-26. https://doi.org/10.1002/ajmg.c.31552.

Mitchell, J., Stanimirovic, R., Klein, B., \& Vella-Brodrick, D. (2009). A randomised controlled trial of a self-guided Internet intervention promoting well-being. Computers in Human Behavior, 25(3), 749-760. https://doi.org/10.1016/j.chb.2009.02.003 
Mitchell, J., Vella-Brodrick, D., \& Klein, B. (2010). Positive psychology and the Internet: A mental health opportunity. Electronic Journal of Applied Psychology, 6(2), 30-41.

Müller, R., Gertz, K. J., Molton, I. R., Terrill, A. L., Bombardier, C. H., Ehde, D. M., \& Jensen, M. P. (2016). Effects of a tailored positive psychology intervention on well-being and pain in individuals with chronic pain and a physical disability: A feasibility trial. The Clinical Journal of Pain, 32(1), 32-44. https://doi.org/10.1097/ AJP.0000000000000225

Müller, R., Segerer, W., Ronca, E., Gemperli, A., Stirnimann, D., Scheel-Sailer, A., \& Jensen, M. P. (2020). Inducing positive emotions to reduce chronic pain: A randomized controlled trial of positive psychology exercises. Disability and Rehabilitation. https://doi.org/10.1080/09638288.2020.1850888

Murray, B., Yashar, B. M., Uhlmann, W. R., Clauw, D. J., \& Petty, E. M. (2013). Ehlers-Danlos syndrome, hypermobility type: A characterization of the patients' lived experience. American Journal of Medical Genetics Part A, 161(12), 2981-2988. https://doi.org/ 10.1002/ajmg.a.36293

NIH U.S. National Library of Medicine. (2018, September 18). EhlersDanlos Syndrome. https://ghr.nlm.nih.gov/condition/ehlers-danlos-syndrome\#statistics.

Nsamenang, S. A., \& Hirsch, J. K. (2015). Positive psychological determinants of treatment adherence among primary care patients. Primary Health Care Research and Development, 16(4), 398-406.

Ostir, G. V., Smith, P. M., Smith, D., \& Ottenbacher, K. J. (2005). Reliability of the positive and negative affect schedule (PANAS) in medical rehabilitation. Clinical Rehabilitation, 19(7), 767-769. https://doi.org/10.1191/0269215505cr894oa

Pavot, W., \& Diener, E. (1993). Review of the satisfaction with life scale. Psychological Assessment, 5(2), 164.

Peters, M. L., Smeets, E., Feijge, M., van Breukelen, G., Andersson, G., Buhrman, M., \& Linton, S. J. (2017). Happy despite pain: A randomized controlled trial of an 8-week Internet-delivered positive psychology intervention for enhancing well-being in patients with chronic pain. The Clinical Journal of Pain, 33(11), 962-975. https://doi.org/10.1097/AJP.0000000000000494

Proyer, R. T., Gander, F., Wellenzohn, S., \& Ruch, W. (2016). Nine beautiful things: A self-administered online positive psychology intervention on the beauty in nature, arts, and behaviors increases happiness and ameliorates depressive symptoms. Personality and Individual Differences, 94, 189-193. https://doi.org/10.1016/j. paid.2016.01.028
Rahman, A., Daniel, C., \& Grahame, R. (2014). Efficacy of an outpatient pain management programme for people with joint hypermobility syndrome. Clinical Rheumatology, 33(11), 1665-1669. https://doi.org/10.1007/s10067-014-2539-9

Ryan, R. M., \& Deci, E. L. (2017). Self-determination theory: Basic psychological needs in motivation, development, and wellness. The Guilford Press. https://doi.org/10.1521/978.14625/28806.

Scheper, M., de Vries, J. E., Verbunt, J., \& Engelbert, R. H. H. (2015). Chronic pain in hypermobility syndrome and Ehlers-Danlos syndrome (hypermobility type): It is a challenge. Journal of Pain Research. https://doi.org/10.2147/JPR.S64251

Schueller, S. M. (2011). To each his own well-being boosting intervention: Using preference to guide selection. The Journal of Positive Psychology, 6(4), 300-313. https://doi.org/10.1080/17439760. 2011.577092

Seligman, M. E. (1972). Learned helplessness. Annual Review of Medicine, 23(1), 407-412.

Sin, N. L., \& Lyubomirsky, S. (2009). Enhancing well-being and alleviating depressive symptoms with positive psychology interventions: A practice-friendly meta-analysis. Journal of Clinical Psychology, 65(5), 467-487. https://doi.org/10.1002/jclp.20593

Tait, R. C., Chibnall, J. T., \& Krause, S. (1990). The pain disability index: Psychometric properties. Pain, 40(2), 171-182.

The Ehlers-Danlos Society. (2018). What are the Ehlers-Danlos Syndromes? Retrieved April 20, 2018, from https://www.ehlers-danlos.com/what-is-eds/.

Vlaeyen, J. W., \& Linton, S. J. (2000). Fear-avoidance and its consequences in chronic musculoskeletal pain: A state of the art. Pain, 85(3), 317-332.

Watson, D., Clark, L. A., \& Tellegen, A. (1988). Development and validation of brief measures of positive and negative affect: The PANAS scales. Journal of Personality and Social Psychology, 54(6), 1063-1070.

Wong, P. T. P. (2011). Positive psychology 2.0: Towards a balanced interactive model of the good life. Canadian Psychology, 52(2), 69-81. https://doi.org/10.1037/a0022511

Publisher's Note Springer Nature remains neutral with regard to jurisdictional claims in published maps and institutional affiliations. 